Full title:

\title{
Stakeholder Engagement: Defining Strategic Advantage for Sustainable Construction
}

\author{
Short title:
}

\section{Stakeholder Engagement for Sustainable Construction}

\author{
Alexander Rodriguez-Melo and S. Afshin Mansouri* \\ Brunel Business School, \\ Brunel University, \\ Uxbridge, Middlesex UB8 3PH, \\ United Kingdom \\ *Corresponding Author, \\ Email: Afshin.Mansouri@brunel.ac.uk \\ Tel: +44-1895-265361, Fax: +44-1895-269775
}

Revised version of the manuscript BSE-10-0082 submitted to:

Business Strategy and the Environment

(Accepted and published in Vol. 20 (2011), pp. 539-552) 


\title{
Stakeholder Engagement: Defining Strategic Advantage for Sustainable Construction
}

\begin{abstract}
Although sustainable development is increasingly becoming part of business plans, it is not clear what makes the economic, social and environmental dynamics strategically compatible. This research examines which of three factors in sustainable development - government policy, managerial attitude and stakeholder engagement - is the most influential on the profitability of companies in the UK construction sector. Quantitative and qualitative analyses were rendered through a survey and semi-structured interviews. Patterns of ambiguity in legislation were discovered as an obstacle for changing the sector's mind-set. Stakeholder engagement was identified as the defining factor increasing managers' awareness, helping legislation to be effectively implemented and making sustainability highly appealing to clients. These findings indicate that to gain competitive advantage, companies should embark in long-term strategic alliances which adopt the proposals of environmental NGOs and closely follow public opinion. Thus, strengthening brand equity, this allows for premium pricing, increased market share, and maximised profit.
\end{abstract}

Keywords: Sustainable construction; Stakeholder engagement; Strategic advantage; United Kingdom

\section{Introduction}

Nowadays, remaining competitive in the market does not depend on financial assets. Sustainable development is increasing pressure on the way companies design their strategies (Elkington, 1997). Nevertheless, the dependency of the social, environmental and economic lines on each other represents the new paradigm to be resolved by strategists. Previous investigations have identified factors in sustainable development which influence a company's performance. However, there is not clarity in identifying the most significant factor, thus clearly exposing a flaw as strategic efforts cannot be used effectively. Moreover, studies have focused on industries such as oil or automobile and the construction sector has not been considered in these investigations. This sector employs c.2.1 million people and contributes more than $£ 100$ billion a year to the UK economy (BERR, 2006). Additionally, buildings are accountable for $50 \%$ of UK carbon emissions, $50 \%$ of water consumption, 35\% of landfill waste and $13 \%$ of all raw materials utilised in the UK (DEFRA, 2007). These facts expose a significant opportunity to explore one of the most controversial issues in business; sustainable development, in the framework of one of the most important sectors; the UK construction sector.

With companies defining objectives in terms of financial results, this research aims to analyze and establish which of three factors in sustainable development - government policy, managerial attitude and stakeholder engagement - yields the greatest improvements in financial performance in the UK's construction sector. The study examines the extent to which each factor is perceived as the most profitable element of sustainable development and analyses any correlations among the three factors.

The remainder of the paper is structured as follows: the next section will analyze previous 
literature and will establish the research's aim and hypotheses. Section 3 will describe the research approach. The findings will be presented and analyzed in Section 4. Finally, Section 5 will discuss the findings of the research and will reflect on the authors' recommendations.

\section{Analysis of Previous Literature}

\subsection{Sustainable Development: a Source for Competitive Advantage}

Conventional economics have worked solely in a monetary world, constantly ignoring societal and environmental needs. This gap highlights the urgency to establish measurable indicators for environmental and social aspects, to make an accurate assessment of a company's practices. A first attempt to define measurements in the social aspect is denoted in the stakeholder theory. The theory classifies the stakeholders' dimensions within the tasks of boards of directors. These dimensions are categorised in, the narrow sense, which includes individuals on which the firm depends for its existence, and the wide sense, which involves individuals who are affected or has an effect in a firm (Freeman and Reed, 1983).

The ample definition of this theory has raised criticism. According to Sternberg (1997), for a corporation is impossible to be equally accountable to all stakeholders. Hence, conflicting interests between different parties cannot serve as a functional model for corporate governance (Sternberg, 1997). These contradictions, nonetheless, can be amalgamated by the concept of sustained competitive advantage originated on a company's resource-base (Barney, 1991). This concept defines value, rarity, inimitability and organisation as the dimensions which position a company ahead of its competitors.

The complexity of the triple bottom line makes sustainability perfectly suitable for Barney's model. Therefore, the companies integrating diverse stakeholders successfully would be able to acquire a privileged position in the market (Hart, 1995). Evidence in the property development industry suggests that integrating sustainability as a distinctive competency in a firm's strategy results in the identification of profitable market niches (Bryson and Lombardi, 2009). This has been tested in the oil industry. Empirical explorations have determined the effectiveness of environmental strategies as part of the resource-based dimensions to obtain competitive advantage (Sharma and Vrandeburg, 1998). Oil industry' investigations offer valuable generalisation. Companies in this industry must focus their strategy in an international scope. Additionally, this industry is one of the most profitable but simultaneously environmentally damaging.

Judge and Douglas (1998) confirm the benefits of sustainability to a company's strategies in other industries. Their quantitative examination not only established sustainability as a base for sustained competitive advantage, but also established the strong and increasing dependency of a company's strategies on the natural environment.

Overall, sustainable development seen from the resource-based perspective of the firm is a determinant of competitive advantage. The next step is to identify the main factors in sustainability which contributes to that advantageous position in the market.

2.2 Sustainability's factors influencing positive financial performance in companies 


\section{Positive Managerial Attitude towards Sustainability}

Environmental awareness is increasing rapidly; therefore companies that do not implement environmental standards in their practices will find their culture to be undermined by employees' personal principles (Hoffman, 1993). The amalgamation of nature and integrity promoted by managerial strategy are necessary if the discourse of ecological and social sustainability is to be maintained (Gladwin, Kennelly and Krause, 1995). This suggests that managerial attitudes towards the natural environment, further than being the force of transformation, can create applicable ideas of profit making through sustainable practices.

Regarding the construction sector, the approach of positive managerial attitude towards "green" corporations as the main factor influencing performance, exhibits a limitation. The construction sector is project-based in nature, consequently each project with its own peculiarities increases the probability of unpredictable events interfering with plans (Bresnen and Marshall, 2001). These issues make the transfer of managerial knowledge more complex than, for instance, the manufacturing sector.

Nonetheless, managerial commitment of belonging to a socially responsible culture has the greatest influence on improving a company's environmental strategies (Catasus, Lundgren and Rynnel, 1997), which as a result brings more economic value to a company's activities despite the industry in which the firm operates (Fineman, 1996). Hoffman (1999), for example, argues that the cultural origins of organisational impacts on the environment depend on managerial decisions. This suggests that environmentally sound strategic preferences overtaken to maximize competitive advantage, has to be negotiated by a dedicated champion (Fineman, 1997). In the construction sector where, for instance, if resources are utilised effectively, a balance between avoiding waste and pollution and achieving a good quality of life can be obtained (Jones and Patterson, 2007).

These arguments advocate that managerial attitude is the primordial factor within sustainability boosting financial performance in a company.

\section{Government Policy}

Businesses awareness of profitable opportunities without regulatory enforcement creates a false supposition about competitiveness in the real market (Porter and van der Linde, 1995). Moreover, company directors tend to assume that all cost-effective advantages for environmental innovation have already been created, thus company's motivation to pursuit sustainable practices is easily overturned (Porter and van der Linde, 1995).

Jaffe et al (1995) study in the manufacturing industry showed that the expenditure created by complying legislation may be equal to the benefits of using it. These results conclude that the role of regulation is to impose a framework of good practice, but its influence on a company's performance is not positive whatsoever. Bonifant, Arnold \& Long (1995), recognise that traditionally, regulation is perceived as an obstacle for a company's practices and development. Conventional legislation, focused solely on cost-impact, delays progress in environmental matters (Porter and van der Linde, 1995). Therefore, the authors argue for a change in the focus of legislation from pollution-prevention to resource-productivity. This new regulation would generate competitive advantage through innovation, e.g. by using 
materials which last longer and can be recycled. Moreover, the most efficient enabler of economic instruments to incentivize innovation comes from conventional policy of direct regulation (Krozer and Neinties, 2006).

This idea can be seen in the UK's construction sector. The key factor of this type of regulation is to force companies to comply with a certain requirement and to provide companies with guidelines that show "how to" achieve the goals established by environmental regulation. It is also complemented by incentives which motivate organisations to fulfil the parameters imposed by government.

For example, under the Code for Sustainable Homes, the UK Government has established a minimum of level 3 on all planning applications for construction. It is an ambitious and demanding objective, which is even more complicated to reach under the climate change levy. This is a tax on electricity used by non-domestic energy users. Despite the tough target, enormous incentives are provided by the Climate Change Agreement, which gives an $80 \%$ discount on the climate change levy charge in exchange for attaining energy-efficiency or carbon emission reduction targets (DEFRA, 2008).

Another example is the business opportunities created by legislation under the Kyoto protocol's carbon trading scheme, which motivates industries to become more aware about environmental protection and furthermore encourages them to be more innovative in the way they operate to raise profits (Hill, 2001; Sathiendrakumar, 2003).

The previous arguments demonstrate that environmental policy is the main source of innovation and, therefore, a source of profitability.

\section{Stakeholders (Environmental NGOs \& General Public)}

Research naming stakeholders as the source of competitive advantage points at two particular stakeholders: the general public and environmental NGOs. Roarty (1997) argues that, since market values are a symbol of society's choice, the general public is the main driver, as it represents consumers' and citizens' preferences for a more sustainable economy. He claims the function of society as the influential factor to become green is the core incentive for businesses to create more environmentally friendly technologies. I.e. if clients are "green", it will be lucrative for organisations to become "green" (Roarty, 1997).

This undermines the criticism of authors such as Hart and Ahuja's (1996) who state that following environmental strategies have limited financial benefits. Moreover, despite the increasing awareness of environmental issues, it is uncertain whether external stakeholders can be recognized as the driving force for corporate, and profitable, environmentalism (Sandhu et al, 2010). Therefore, environmental strategies would not represent the objective of sustainable development (Hart, 1997).

As demonstrated by Maxwell et al (1997); Sharma, Pablo \& Vredenburg (1999) nonetheless, further improvement in financial performance can be achieved by implementing marketing strategies created to satisfy the need of the general public and environmental NGOs. They state that these strategies create value by improving performance through reducing costs of input resources, higher efficiency, lower energy consumption, waste reduction and differentiated products. 
It has been argued moreover, that measuring and satisfying the aspirations of stakeholders forms an important part of companies' performance (Welford et al, 2008). These tactics improve levels of corporate reputation and brand equity through products derived from organic manufacture or recycled goods, which lead to premium prices due to their sustainable attributes (Maxwell et al, 1997). In industries such as hospitability, it has been discovered that by displaying an environmentally focused image, a firm strengthens its competitiveness through cost-savings, improved reputation and becoming a more preferred employer, partner and supplier (Heikkurinen, 2010). These marketing strategies have helped the oil industry to continue with its profitable practices, and have contributed to its expansion (Ihlen, 2009). Cases like the poor environmental and social performance of Royal Dutch Shell in Nigeria support this argument. Social unrest in this case provoked a fundamental transformation in the corporate strategy of one of the biggest corporations, forcing it to augment its involvement with stakeholders (Wheeler, Fabig \& Boele, 2002). The contribution of the gas $\&$ power business unit of Shell, in which sustainable technologies are embodied, improved the total revenue of the firm by more than $\$ 2.7$ billion in 2007. Conversely, the oil sand unit, one of the most polluting divisions, only contributed $\$ 0.6$ billion (Royal Dutch Shell plc, 2008)

Therefore, it can be argued that stakeholders are the major force in sustainable development driving financial improvements in a firm.

\subsection{Research Aim, Objectives and Hypotheses}

The efforts to analyse the integration of factors in corporate strategy only show that there is a constant conflict of values between organisational members and organisational dynamics. These efforts therefore do not explain how to make sustainability profitable. Hence, the role that external constituencies have in the improvement of corporate environmentalism and sustainable development needs to be understood (Newton and Harte, 1997)

With companies establishing their objectives in relation to financial results, the aim of this research is to analyze, investigate and establish which of the 3 factors in sustainable development yields the greatest improvement in financial performance in the UK's construction sector. This aim embroils the following hypotheses:

Hypothesis 1: Positive managerial attitude increases a company's profitability more than Government policy and Stakeholders engagement

Hypothesis 2: Government policy increases a company's profitability more than managerial attitude and Stakeholders engagement

Hypothesis 3: Stakeholders engagement (Environmental NGOs \& General Public) increase a company's profitability more than managerial attitude and Government policy

To test the hypotheses, the aim will encompass the consequent objectives:

1. To establish the extent to which decision-makers perceive government policy in relation to sustainable construction as a guideline to improve the company's performance.

2. To investigate the extent to which stakeholders (Environmental NGOs, the general 
public), are pushing firms to understand that environmental procedures are a more profitable method of creating business.

3. To examine the extent to which positive managerial attitude towards sustainability contributes to the organisation in order to increase revenue.

4. To establish whether there is any correlation between the three factors.

\section{Research Approach}

This research implements methodological triangulation, rendered in pilot surveys, a questionnaire (Appendix A) and semi-structured interviews (Appendix B). Quantitative research facilitated the discovery of the most influential factor. The interviews helped to confirm the validity of the information (Seale, 1999). Moreover, as analysis of the relationships between diverse managerial perceptions was needed for the investigation, the interviews helped to interpret the "how" and "why" issues behind these correlations arise (Bell and Bryman, 2007). This exhaustive approach has successfully examined linkages between environmental strategies, the development of capabilities and their competitive outcomes in the oil industry (Sharma and Vrandeburg, 1998).

The questionnaires were aimed at senior project managers, whereas the interviews were directed at company's strategists. Questions of classification in the questionnaire such as age, position in the company and experience, helped to increase internal validity. Therefore, despite people, times and settings, a generalizable conclusion was established (EasterbySmith, Thorpe and Jackson, 2008).

In total 30 companies were approached in the UK, these companies covered more than 14 services, e.g. engineering consultancy or demolition. External validity was also increased in three ways: firstly, $50 \%$ of the survey approached small and medium sized (SME) companies and the other 50\% approached large companies. This justified the generalization of the findings (Maylor and Blackmon, 2005). Secondly, all the respondents worked in the private sector, making the data more precise. For example, conflicting goals between local government and businesses were avoided (Porter and van der Linde, 1995). Thirdly, a wide pool of UK respondents was covered; hence there is a generalizability of the results according to the focal study (Kervin, 1992).

\subsection{Pilot work, Questionnaire and Sampling design}

To know if the information gathered through the construction of the questionnaire would yield the results expected, a pilot survey was used. This improved the design and organisation of questions, and decreased non-response rates (Oppenheim, 1997). Representativeness and precision were achieved by gathering the responses through one group of respondents only (Senior Project managers). Thus, possible bias created by the effects of heterogeneity in opinions of different groups was dramatically reduced (Easterby-Smith, Thorpe and Jackson, 2008).

As financial performance is the ultimate goal of a company (Fineman, 1996; Bonifant, Arnold, \& Long, 1995; Hart, 1995), the questionnaire was designed establishing economic improvement as the requirement to be fulfilled. Nine questions were created, assigning three statements to each factor, this acted as a triangulation parameter (Maylor and Blackmon, 
2005). The survey was distributed in two ways. Companies were identified and contacted by email. Subsequently, an online survey was sent aiming to approach project managers. Additionally, project managers were approached directly on the construction sites. In total 100 managers were contacted, obtaining a final rate of response of $51 \%$.

\subsection{Semi-structured interviews}

Seven interviews were conducted. These involved projective questions which were moderately vague or apparently unconnected, allowing the responses to be indicatives of observation, personal value or drive (Johnson and Harris, 2002). Decision makers and strategists of large companies were approached, due to them having a greater impact on the sector and having more influence on different stakeholders.

As one group of respondents could have produced biased data, the scope of responses from different managerial roles was enlarged. The interviews were carried out with two senior project directors, two senior contract managers, two commercial managers and a group interview with three participants.

\section{Data Analysis and Results}

\subsection{Quantitative Analysis}

The data gathered through questionnaires was analysed using the Statistical Package for Social Sciences (SPSS). In total nine outliers were removed. The t-test was selected as the most convenient method of achieving the objectives of the investigation. The practicality of the t-test is enhanced as it requires a small sample size (Field, 2005). Furthermore, as the same participants were used to avoid unsystematic variation from arbitrary aspects that existed between experimental settings, a dependent t-test was implemented at confidence intervals of $99 \%$. To confirm the homogeneity of variance in the groups, this type of t-test was selected to obtain more accurate results (Field, 2005).

Normal distribution was analysed through the Kolmogorov-Smirnov test at $95 \%$ confidence. The Kolmogorov-Smirnov statistics are non-significant (Sig. is above 0.05 in all variables) which indicates that they are normally distributed (Table 1).

\section{Insert table 1 about here}

The t-test (table 2) determined that participants highlighted a large positive influence from stakeholders on companies' financial performance, than managerial attitude $(t=3.208)$. An even greater positive influence was found from stakeholders, than Government policy $(t=3.956)$. The reliability of the results is confirmed by their significance ( $p)$. Stakeholders showed $p=0.000$ and managerial attitude showed $p=0.003$. These values are statistically meaningful as they are below $\mathrm{p}=0.01$ (Field, 2005).

\section{Insert table 2 about here}

The Effect size was calculated the equation: $\mathrm{r}=\sqrt{[} t^{2} /\left(t^{2}+d f\right)$, where $d f$ is degree of freedom to 
realize the importance of these results in practical terms (Field, 2005). A large effect is $r=0.5$; a medium, $r=0.3$; and a small, $r=0.1$. In this case, the effect of Stakeholder/Management had a large effect and Stakeholder/Government had an extremely large effect (Cohen, 1988). Thus, the only hypothesis accepted is number three, as:

- $t($ Stakeholders-3,956) $>t($ Management-3.208), $r=0.45, p=0.003$; and

- $t($ Stakeholders-3,956) $>t$ (Government-1.642), $r=0.53, p=0.000$

A Pearson's correlation analysis (Table 3) showed that the participants' age and experience do not have any affect in the perception of the three factors studied. In the group of variables, there was only one noteworthy positive correlation between stakeholders and managerial attitude, $0.467, \mathrm{p}=0.002<\mathrm{p}=0.01$ (Table 3 ). This does not explain causality. However, as established by the t-test, it could be assumed that stakeholders is the factor predefining the change on managerial attitude.

\section{Insert table 3 about here}

A linear regression analysis revealed that stakeholders account for approximately $20 \%$ of positive managerial attitude towards sustainable development $\left(\mathrm{R}^{2}=0.198\right)$. The model specifies a Y-intersect $b 0=1.296$ (Table 4), which indicates that, if there were no groups of stakeholders increasing manager awareness, there would only be about 1.3 managers with a positive attitude towards sustainability. However, the level of significance of this result slightly exceeds the maximum of $p=0.05$ with a value of $p=0.052$, meaning that it might not reflect a genuine effect in practice.

\section{Insert table 4 about here}

Nevertheless, the gradient of the regression line $b 1=0.585$ shows a genuine effect in real practice (sig. $p=0.002<p=0.05$ ). It can therefore be inferred that per each group of stakeholders, there would be 0.585 managers with a positive attitude towards sustainability, i.e. by having 100 groups of stakeholders; the number of managers with environmentally friendly perceptions would increase to around 60:

$$
\begin{aligned}
\text { Environmentally friendly managers } & =b 0+(b 1 \times \text { Stakeholder groups }) \\
& =1.296+(0.585 \times 100) \approx 60
\end{aligned}
$$

\subsection{Qualitative Analysis}

Grounded theory was selected to analyze the interviews. Through its systematic process grounded theory offered a meaningful guide to explore thoroughly the perceptions embedded in this research (Strauss and Corbin, 1998). For each interview, an open coding procedure was performed. Data was refined into incidents, facts, actions and acts to examine the relevance of their characteristics (Strauss and Corbin, 1998). Subsequently, these factors were conceptualised and compared, to create categories which helped to classify the data (Strauss and Corbin, 1998).

On average 17 categories were established from each interview. These categories were then 
grouped into subcategories to explain "where", "why" and "how" a phenomenon is likely to occur (Strauss and Corbin, 1998). Overall eight significant patterns were documented:

1. $85 \%$ of managers recognise ethical issues as part of the sustainability agenda.

2. $42 \%$ of managers recognised government as important. However:

3. $42 \%$ perceived Government as unclear and unspecific, thus leaving gaps for misinterpretation.

4. $57 \%$ of managers agreed that a shift in mindset is needed if progress in sustainability is to be reached.

5. $42 \%$ of managers saw sustainability as a primary issue because is of great significance for stakeholders.

6. In order to increase profit, all the managers recognised a high level of dependency on stakeholders. Mainly from the focus of three aspects:

a. Client specifications - since customers are becoming more knowledgeable stakeholders.

b. Good publicity for the company, which results in a good reputation and an increase in number of contracts awarded.

c. Recognition as a sustainable organisation, thus increasing market share.

7. Although $42 \%$ of managers suggested long term planning, all the managers clearly identified three aspects as necessary to use in order to progress in sustainability:

a. Enforcement of the standards once they are in place.

b. Leadership that enables the objectives of the standards to be achieved.

c. Effective communication of ideas within the company.

8. $100 \%$ of managers asserted the following statements:

a. Perceived sustainability as a new and complex field.

b. Acknowledged costs as the most critical aspect when justifying sustainable practices.

c. Acknowledged lack of education as the most significant hindrance in creating sustainable solutions within the firms.

To recapitulate, through the quantitative analysis, stakeholders were established as the primary factor influencing a company's profitability. Moreover, a positive correlation was found, hinting at a $20 \%$ influence of stakeholders on managerial attitude towards sustainability. The qualitative analysis demonstrates eight significant patterns explaining the phenomena of sustainability's factors in corporate strategy. Most of these patterns refer to the great importance of stakeholders, the identification of hindrances in sustainable practices and the possible solution to tackle these obstacles. 


\section{Discussion and Research Contributions}

The research's statistical analysis suggested managerial attitude as more influential than government policy. However, the low significance (p), undermines the reliability of this conclusion. This ambiguity is supported by the interviewees' responses. $42 \%$ of managers claimed that legislation is "probably" the driver of the sustainable trend. Nonetheless, other $42 \%$ of managers referred to the lack of clarity in legislation, noting that it is vague, and that has negative consequences on managers' perception. One manager noted:

"I find it very difficult. We have departments to guide us, so before legislation come into effect, we will have the procedures in place to make sure that happens. The difficulties about that are the interpretations".

These assertions expose an important gap in the current governmental approach to sustainability. It can be argued that lack of precision in legislation erodes the arguments in favour of Government being the source of competitive advantage (Jaffe et al, 1995)

The statistical analysis cannot affirm either managerial attitude or government policy as the most relevant factor. However, stakeholders were clearly established by the analysis as the primary factor enhancing a company's performance. The interviews analysis explains this outcome. Clients were often referred to by the interviewees as more conscious stakeholders who are driving the company's standards:

"Any business needs to respect the decisions of stakeholders. We welcome those because that means that everybody is working together. If our stakeholders have an input in which the way the company is run, then the outcome of the company is much better".

All participants claimed that a good relationship with stakeholders enhances considerably the reputation of the company. As a result, more contracts are generated, thus increasing profit. This suggests that stakeholders are the main contributor in converting sustainable development into the sought resource-based competitive advantage (Hart, 1995). The manager from one of the most successful construction companies in the UK noted:

"Obviously people want to work with us because we are not driven only by cost. If you want to be part of sustainability, you first start to develop working relationships with clients. They would want to come back to you because you do a good job, so it is a differentiator".

Some managers stated stakeholders' persuasiveness in turning strategists in favour of social and environmental practices:

"because of environmental protests is that the company got involved with sustainability, that has changed everybody to say, ok what is this particular element?, why not being environmentally minded in that local system? And this is how the whole company operates"

This proposes that through stakeholder intervention managers become more concerned about sustainability issues. This finding is very significant as most of the interviewees identified ignorance as the major hindrance in creating sustainable and profitable ideas. This result explains the correlation which indicates that $20 \%$ of managerial attitude towards 
sustainability is derived from the influence of stakeholders (Roarty, 1997). Significant improvements are generated through these assumptions, as $100 \%$ of interviewees strongly agreed with the relevance of leadership in the long-term strategy achieving and disseminating sustainable ideas.

Previous research disagreed in establishing the most influential factor in sustainability as the source of competitive advantage. This research has identified this factor - stakeholder engagement. The study has established the extent to which and how Stakeholders provide competitive edge to companies in the construction sector. Moreover, it has been identified that dynamic conflicts between government policy and companies responsiveness is affecting the implementation of effective regulation, thus hampering efforts to improve sustainable practices. It could be questioned however what the implications of these results for companies are and how these findings can be put in practice by strategists.

The rapid pace at which concern for sustainability issues is growing means that, if companies intend to remain competitive, a long-term strategy involving stakeholders must be developed. As stated by managers and demonstrated by the study, firms that implement sustainable strategies are more appealing to clients' demands (Maxwell et al, 1997; Sharma, Pablo \& Vredenburg, 1999), this enhances reputation and consequently leads to profit maximisation (Maxwell et al, 1997; Heikkurinen, 2010); as asserted by another manager:

"I think sustainability is just good business, it builds relationships and reputation, you cannot buy that, it takes a long time to build it. Once you have got reputation for leading the way in, it just reminds everybody that we are up there".

Moreover, additional features, such as lack of education, can be counterbalanced if strong relationships are created between the stakeholders and the firm. If the barrier of ignorance is removed, mutual benefits will be achieved. This study demonstrates the need to strengthen strategic alliances between these three exclusive parties (companies, environmental NGOs and the general public). The study reveals that aspects such as publicity and reputation are extremely vulnerable to public opinion and have strong effects on a firm's performance in the construction sector.

The idea of identifying stakeholders as the most valuable factor to obtain competitive advantage means that companies' resources can be utilised more effectively. Vis-à-vis other sectors, construction possesses a unique advantage. The authors recommend that strategists should exploit the direct contact, extensive geographical reach and project-base nature of the construction sector to enhance their connection with the community. E.g. although the impact of one project is negligible, a large company developing 5000 projects possesses direct contact with a huge proportion of local communities. Thus, the results of a micro level approach can be reflected in a macro level magnitude, as brand equity will be constantly strengthened by the simple fact of taking into account general public opinion. For instance, if a company is building a library in a university, the stakeholders most affected by its practices would be the academic community, whose understanding of sustainability issues would have a higher possibility of solving environmental, social and economic incongruence. If the company engages with these types of stakeholders, substantial information would be acquired to improve sustainable practices.

This approach should be deeply entrenched in the corporate strategy of the firms, hence 
underpinning three crucial aspects of the companies' competitiveness. Firstly, the community will feel respected; considerably improving the company's reputation. Secondly, valuable information in relation to sustainability will be gathered and evaluated at a relatively low cost. This information will not only generate a database of possible solutions to the intricacies in sustainable development, but will also gather the consensus of prospect clients' needs, which would further help companies to tailor their services more effectively. Thirdly, this strategy will reduce the hindrance of lack of communication and education that has decelerated progress in innovation to achieving sustainable development. These benefits will also be obtained through strategic alliances with Environmental NGOs. These organisations possess a higher level of proficiency when dealing with environmental problems due to their long trajectories having made them experts in the field (Miles and Friedman, 2002), thus helping companies to achieve sustainable targets.

By strengthening these relationships, the creation of the sought sustainable society is accelerated. Nevertheless, other parties, such as government and leaders in sustainability, are still important contributors when solving this conundrum. This investigation also exposes gaps, such as lack of clarity in legislation, which must be addressed in due course. It is recommended that if environmental regulation is seeking to transform current business practices into more sustainable processes, it is necessary to revise the effectiveness and interpretation of these guidelines.

Two promising investigations yielded by the research were the correlation between Stakeholders and Managerial attitude; and the ambiguity of legislation. Hence, it would be important to investigate the dynamics behind these elements and their effects on the implementation of sustainable practices. 


\section{References}

Barney J. 1991. Firm Resources and Sustained Competitive Advantage Journal of Management 17 (1): 99 -120.

Bresnen M. and Marshall N. 2001. Understanding the diffusion and application of new management ideas in construction Engineering, Construction and Architectural Management 8 (5): 335-345.

Bonifant B. C. Arnold M. B. and Long F. J. 1995. Gaining Competitive Advantage through Environmental Investments Business Horizons (July-August): 39-47.

Bryson J. and Lombardi R. 2009. Balancing Product and Process Sustainability Against Business Profitability: Sustainability as a Competitive Strategy in the Property Development Process Business Strategy and the Environment 18 (2) 97-107.

Catasus B. Lundgren M. and Rynnel H. 1997. Environmental Managers' Views on Environmental Work in Business Context Business Strategy and the Environment 6: 197 $-205$.

Fineman S. 1996. Emotional Subtexts in Corporate Greening Organization Studies 17 (3): $479-500$.

Fineman S. 1997. Constructing the Green Manager British Journal of Management 8: 3138

Freeman R. E. and Reed D. L. 1983. Stockholders and Stakeholders: A New Perspective on Corporate Governance California Management Review 25 (3): 88 - 106.

Gladwin T. N. Kennelly J. J. and Krause T. 1995. Shifting paradigms for sustainable development: Implication for Management Theory and Research. Academy of Management Review 20 (4): 874 - 907.

Hart S. 1995. A Natural-Resource-Based View of the Firm The Academy of Management Review 20 (4): 986-1014

Hart S. and Ahuja G. 1996. Does It Pay To Be Green? An Empirical Examination of the Relationship between Emission Reduction and Firm Performance Business Strategy and the Environment 5: 30-37.

Hart S. 1997. Beyond Greening: Strategies for a Sustainable World Harvard Business Review 75 (1): $66-76$.

Heikkurinen P. 2010. Image Differentiation with Corporate Environmental Responsibility Corporate Social Responsibility and Environmental Management 9 (2) 142-152.

Hill M. R. 2001. Sustainability, Green House Gas Emissions and International operations management International Journal of Operations \& Production Management 21 (12): $1503-1520$. 
Hoffman A. J. 1993. The importance of fit between individual values and organisational culture in the greening of industry Business Strategy and the Environment 2 (4): 10 - 18.

Ihlen O. 2009 The Oxymoron of 'Sustainable Oil Production': The Case of the Norwegian Oil Industry Business Strategy and the Environment 18: 53 - 63

Jaffe A. B, Peterson S. R, Portney P. R. and Stavins R. N. 1995. Environmental Regulation and the Competitiveness of U.S. Manufacturing: What Does the Evidence Tell Us? Journal of Economic Literature, 33 (1): 132-163.

Jones P. Patterson J. 2007. The Development of a Practical Evaluation Tool for Urban Sustainability Indoor and Built Environment 16 (3): 255-272.

Judge W. and Douglas T. 1998. Performance Implications in Incorporating Natural Environmental Issues Into the Strategic Planning Process: An Empirical Assessment Journal of Management Studies 35 (2): 241 - 262.

Krozer Y. and Neinties A. 2008. Environmental Policy and Innovation Business Strategy and the Environment 17 (4) 219-229.

Maxwell J. et al. 1997 Green Schemes: Corporate Environmental Strategies and Their Implementation California Management Review 39 (3): 116 -134.

Miles S. and Friedman A. 2002. Development stakeholder theory Journal of Management Studies 39 (1): 1 - 21.

Newton T. and Harte G. 1997. Green Business: Technicist Kitsch? Journal of Management Studies 34 (1): 75-98.

Porter M. and van der Linde C. 1995. Green and competitive: Ending the Stalemate Harvard Business Review (September/October) 119-134.

Roarty M. 1997. Greening business in a market economy European Business Review 97 (5): 244-254.

Sandhu S. Ozanne L. Smallman C. Cullen R. 2010. Consumer Driven Corporate Environmentalism Business Strategy and the Environment 19 (6): 356 -366.

Sathiendrakumar R. 2003. Greenhouse emission reduction and sustainable development International Journal of Social Economics 30 (12): 1233 - 1248.

Sharma S. and Vredenburg H. 1998. Proactive Corporate Environmental Strategy and the Development of Competitively Valuable Organizational Capabilities Strategic Management Journal 19: 729-753.

Sharma S. Pablo A. L. and Vredenburg H. 1999. Corporate Environmental Responsiveness Strategies: The Importance of Issue Interpretation and organisational context The Journal of Applied Behavioural Science 35 (1): 87-108. 
Sternberg E. 1997. The defects of Stakeholder Theory Scholarly Research and Theory Papers 5 (1): 3 -10.

Wheeler D. Fabig, H. \& Boele R. 2002. Paradoxes and Dilemmas for Stakeholder Responsive Firms in the Extractive Sector: Lessons from the Case of Shell and the Ogoni Journal of Business Ethics 39: 297-318.

Welford R. Clifford C. and Man M. 2008. Priorities for Corporate Responsibility: a Survey of Business and Their Stakeholders Corporate Social Responsibility and Environmental Management 15 (1) 52-62.

Department for Business Enterprise \& Regulatory Reform (BERR) 2006. Review of sustainable construction: London. http://www.berr.gov.uk/files /file34979.pdf. [29th December 2007].

Department for Environment, Food and Rural Affairs (DEFRA) 2007. Draft Strategy for Sustainable Construction: a Consultation Paper: London. http://www.berr.gov.uk/files/file40641.pdf. [28th December 2007].

Department for Environment, Food and Rural Affairs (DEFRA) 2007. Climate Change Agreements - Result of the Second Target Period: Period Assessment: London. http://www.defra.gov.uk/Environment/ climatechange/uk/business/ccl/pdf/cca-jul05.pdf. [28th July 2008].

Royal Dutch Shell plc. 2008. Annual Review and Summary Financial Statements 2007: London. http://www-static.shell.com/static/investor/downloads/financial_information /reports/2007/2007_annual_review.pdf. [10 ${ }^{\text {th }}$ August 2008].

Bell E. and Bryman A. 2007. Business research methods. $4^{\text {th }}$ edn. Oxford: Oxford University Press.

Cohen J 1988. Statistical power analysis for the behavioural sciences. $2^{\text {nd }}$ edn. New York: Academic press.

Elkington J. 1997. Cannibals with Forks: The Triple Bottom Line of the $21^{\text {st }}$ Century Business. $1^{\text {st }}$ edn. Oxford: Capstone Publishing Limited.

Easterby-Smith M. Thorpe R. and Jackson P. R. 2008. Management Research. $3^{\text {rd }}$ edn. London: SAGE Publications Ltd.

Field A. 2005. Discovering Statistics Using SPSS. $2^{\text {nd }}$ edn. London: SAGE Publications Ltd.

Johnson P. and Harris D. 2002. 'Qualitative and quantitative issues in research design', in: Partington, D. (ed) Essential Skills for Management Research. London: SAGE Publications ltd, pp. $99-116$.

Kervin J. B. 1992. Methods for Business Research. $1^{\text {st }}$ edn. New York: HarperCollins 
Publishers Inc.

Maylor H. and Blackmon H. 2005. Researching Business and Management. $1^{\text {st }}$ edn. New York: Palgrave Macmillan.

Oppenheim A. N. 1997. Questionnaire design, Interviewing and Attitude Measurement. $3^{\text {rd }}$ edn. London: Continuum.

Seale C. 1999. The Quality of Qualitative Research. $1^{\text {st }}$ edn. London: SAGE Publications ltd.

Strauss A and Corbin J 1998. Basis of Qualitative Research: Techniques and Procedures for Developing Grounded Theory. $2^{\text {nd }}$ edn. London: SAGE Publications ltd. 


\section{Project title:}

\section{ESTABLISHING THE STRATEGIC ADVANTAGE IN SUSTAINABLE CONSTRUCTION.}

This survey aims to measure which of 3 factors adjusts itself better within the strategicplanning framework of the company as the closest motivator to improve financial performance in relation to sustainable development. These factors are:

1 Government regulation related to sustainability

2 Positive managerial attitude towards sustainability

3 Stakeholders' view (Public and environmental NGOs).

You will be asked to consider the degree to which these factors affect environmental decisions in the firm, from a profitable perspective.

Please grade the importance of the following statements from 1 to 5.1 is the least important and 5 the most important.

1. Government regulation related to sustainable construction, improves the firm's financial performance

$$
1() 2() 3() 4() 5()
$$

2. Lack of Managers with positive attitude towards sustainability is one of the main obstacles to increase profitability in the company

$$
\text { 1( )2( )3( )4( )5( ) }
$$

3. Reputation as a leader in sustainability helps to improve the company's financial profile

$$
\text { 1( )2( )3( )4( )5( ) }
$$

5. The Company responds positively to government sustainable development legislation, even if it affects profitability within the firm

$$
1() 2() 3() 4() 5()
$$

6. The firm recognises Managers with positive attitude towards sustainability, as an important asset to improve financial performance as opposed to government regulation or stakeholders' view

$$
1() 2() 3() 4() 5()
$$

Please specify on a scale from 1 to 7 how strongly you agree with the following statements, 1 indicating disagreement and 7 indicating strong agreement.

7. The Company develops new resources, activities and capabilities to satisfy stakeholders' preferences, in order to increase revenue

$$
\text { 1( )2( )3( )4( )5( )6( )7( ) }
$$

8. Only if environmental policies proposed by the Government help the company to increase revenue, then the firm will improve its sustainable practices. 


\section{1( )2( )3( )4( )5( )6( )7( )}

9. Managers with positive attitude towards sustainability are influential on increasing revenue through the development of innovative environmentally sustainable practices within the firm

$$
\text { 1( )2( )3( )4( )5( )6( )7( ) }
$$

10. A close relationship with the public and environmental NGOs increases profitability for the firm.

$$
\text { 1( )2( )3( )4( )5( )6( )7( ) }
$$

11. Are there any positive or negative aspects you would like to highlight regarding the influence of sustainability in the decisions made by the organisation?

12. Would you be willing to participate in an interview? YES( ) $\mathrm{NO}($ )

13. Could you recommend any other project managers who might be interested in completing this questionnaire:

- Could you please provide some additional information:

14. Position within the company:

15. Type of project:

16. Location of project:

17. Number of employees in the project:

18. Time of experience working in the construction sector:

19. Gender: Male( ) Female( )

20. Age: Under 30( ), 31-40( ), 41-50( ), 50-60( ), over 60( ). 


\section{- S.Q: Secondary Question}

1. How would you describe this company?

S.Q Do you think is on the environmentally friendly side?

2. How would you define sustainable development?

3. What are the constraints of applying sustainable practices in the company?

S.Q Are these constrains based on financial result?

4. How does the firm negotiate with suppliers regarding environmental sustainability?

5. In general terms, what is the company's perception of sustainability development?

6. How easy is it to find employees with positive attitude towards sustainability?

S.Q How does the firm benefit from employing these people?

7. Could you give me an example of one way in which the company has benefited financially from sustainable development?

8. How easy do you find it to keep up with Government environmental legislation?

S.Q How employees keep up with it?

9. How do you encourage employees to be aware of sustainability?

10. How does the company engage with environmental NGOs or the general public?

S.Q Do you think they have any impact in the company's practices?

11. How do you become aware of environmentally sustainable practices?

12. Which element of Government environmental legislation do you believe to be the most influential for the firm?

13. Could you give me some examples of innovation in sustainable practice and their impacts on the company?

14. How would you define the company's culture in relation to sustainable development?

15. What are the financial drawbacks of using sustainable practices?

16. How do you think the company may create new business opportunities using sustainable practices?

17. What is the company's policy regarding practices of environmental sustainability?

18. How do you think sustainable development influences productivity in the firm?

19. How easy is it to design criteria to undertake sustainable practices?

S.Q what are the criteria for undertaking environmentally sustainable practices?

20. Would you like to add any other comments?

\section{TABLES}


Table 1: Test of Normal Distribution

\begin{tabular}{|l|r|r|r|r|r|r|}
\hline & \multicolumn{3}{|c|}{$\begin{array}{c}\text { Kolmogorov- } \\
\text { Smirnov }\end{array}$} & \multicolumn{3}{c|}{ Shapiro-Wilk } \\
\cline { 2 - 8 } & Statistic & df & Sig. & Statistic & df & \multicolumn{1}{|c|}{ Sig. } \\
\hline Government & 0.057 & 41 & 0.2 & 0.983 & 41 & 0.78 \\
\hline Management & 0.066 & 41 & 0.2 & 0.981 & 41 & 0.7 \\
\hline Stakeholders & 0.107 & 41 & 0.2 & 0.974 & 41 & 0.45 \\
\hline
\end{tabular}

Table 2: t-test's results

\begin{tabular}{|c|c|c|c|c|c|c|c|c|}
\hline & Mean & \multirow{2}{*}{$\begin{array}{c}\text { Std. } \\
\text { Deviation }\end{array}$} & $\begin{array}{c}\text { Std. } \\
\text { Error Mean }\end{array}$ & \multicolumn{2}{|c|}{$99 \%$ Confidence } & t & df & Sig (p) \\
\hline $\begin{array}{c}\text { Management - } \\
\text { Government }\end{array}$ & 0.21 & 0.826 & 0.127 & -0.135 & 0.553 & 1.64 & 41 & 0.108 \\
\hline $\begin{array}{c}\text { Stakeholder - } \\
\text { Management }\end{array}$ & 0.22 & 0.450 & 0.069 & 0.035 & 0.410 & 3.20 & 41 & 0.003 \\
\hline $\begin{array}{c}\text { Stakeholder - } \\
\text { Government }\end{array}$ & 0.43 & 0.708 & 0.109 & 0.137 & 0.727 & 3.95 & 41 & 0.000 \\
\hline
\end{tabular}

Table 3: Pearson Correlation Results

\begin{tabular}{|c|c|c|c|c|c|c|}
\hline \multicolumn{2}{|c|}{} & Government & Management & Stakeholder & Experience & Age \\
\hline \multirow{2}{*}{ Government } & Correlation & 1.000 & -0.019 & 0.168 & -0.180 & -0.170 \\
\cline { 2 - 7 } & Sig. & & 0.903 & 0.286 & 0.255 & 0.282 \\
\hline \multirow{2}{*}{ Management } & Correlation & -0.019 & 1.000 & 0.467 & -0.170 & -0.111 \\
\cline { 2 - 7 } & Sig. & 0.903 & & 0.002 & 0.281 & 0.484 \\
\hline \multirow{2}{*}{ Stakeholder } & Correlation & 0.168 & 0.467 & 1.000 & -0.055 & -0.023 \\
\cline { 2 - 7 } & Sig. & 0.286 & 0.002 & & 0.731 & 0.884 \\
\hline \multirow{2}{*}{ Experience } & Correlation & -0.180 & -0.170 & -0.055 & 1.000 & 0.860 \\
\cline { 2 - 7 } & Sig. & 0.255 & 0.281 & 0.731 & & 0.046 \\
\hline \multirow{2}{*}{ Age } & Correlation & -0.170 & -0.111 & -0.023 & 0.860 & 1.000 \\
\cline { 2 - 7 } & Sig. & 0.282 & 0.484 & 0.884 & 0.046 & \\
\hline
\end{tabular}

Table 4: Linear Regression Model 1: Stakeholder \& Management 


\begin{tabular}{|c|c|c|c|c|}
\hline \multicolumn{5}{|c|}{ Summary } \\
\hline Model & $\mathbf{R}$ & $\mathbf{R}^{\wedge} \mathbf{2}$ & $\begin{array}{c}\text { Adjusted } \\
\mathbf{R}^{\wedge} \mathbf{2}\end{array}$ & $\begin{array}{c}\text { Std. } \\
\text { Error of }\end{array}$ \\
\hline 1 & $.467^{\mathrm{a}}$ & 0.218 & 0.198 & 0.427 \\
\hline
\end{tabular}

a. Predictors: (Constant), Stakeholder

\begin{tabular}{|c|c|c|c|c|c|}
\hline \multicolumn{7}{|c|}{ ANOVA $^{\mathbf{b}}$} \\
\hline Model & $\begin{array}{c}\text { Sum of } \\
\text { Squares }\end{array}$ & df & $\begin{array}{c}\text { Mean } \\
\text { Square }\end{array}$ & F & Sig. \\
\hline Regression & 2.034 & 1 & 2.034 & 11.133 & $.002^{\mathrm{a}}$ \\
\hline Residual & 7.308 & 40 & 0.183 & & \\
\hline Total & 9.343 & 41 & & & \\
\hline
\end{tabular}

a. Predictors: (Constant), Stakeholder

b. Dependent Variable: Management

\section{Coefficients $^{\mathrm{a}}$}

\begin{tabular}{|c|c|c|c|c|c|}
\hline & \multicolumn{2}{|c|}{$\begin{array}{c}\text { Unstandardised } \\
\text { Coefficients }\end{array}$} & \multicolumn{2}{|c|}{$\begin{array}{c}\text { Standardized } \\
\text { Coefficients }\end{array}$} & \multicolumn{2}{|c|}{} \\
\cline { 2 - 5 } & B & Std. Error & Beta & & \multicolumn{2}{|c|}{} \\
\hline Constant & 1.296 & 0.646 & & 2.006 & 0.052 \\
\hline Stakeholder & 0.585 & 0.175 & 0.467 & 3.337 & 0.002 \\
\hline
\end{tabular}

a. Dependent Variable: Management

Table 5: Data Features

\begin{tabular}{|c|c|c|c|c|c|c|}
\hline & \multicolumn{2}{|c|}{ Government } & \multicolumn{2}{c|}{ Management } & \multicolumn{2}{c|}{ Stakeholder } \\
\cline { 2 - 7 } & Statistic & $\begin{array}{c}\text { Std. } \\
\text { Error }\end{array}$ & Statistic & $\begin{array}{c}\text { Std. } \\
\text { Error }\end{array}$ & Statistic & $\begin{array}{c}\text { Std. } \\
\text { Error }\end{array}$ \\
\hline Mean & 3.230 & 0.103 & 3.439 & 0.074 & 3.662 & 0.059 \\
\hline Lower Bound & 2.953 & & 3.240 & & 3.504 & \\
\hline Upper Bound & 3.507 & & 3.638 & & 3.821 & \\
\hline Median & 3.165 & & 3.365 & & 3.700 & \\
\hline Variance & 0.442 & & 0.228 & & 0.145 & \\
\hline Std. Deviation & 0.665 & & 0.477 & & 0.381 & \\
\hline Minimum & 2.030 & & 2.700 & & 3.000 & \\
\hline Maximum & 4.400 & & 4.400 & & 4.330 & \\
\hline Range & 2.370 & & 1.700 & & 1.330 & \\
\hline Interquartile Range & 0.910 & & 0.670 & & 0.520 & \\
\hline Skewness & 0.095 & 0.365 & 0.415 & 0.365 & -0.177 & 0.365 \\
\hline Kurtosis & -0.824 & 0.717 & -0.556 & 0.717 & -0.845 & 0.717 \\
\hline
\end{tabular}

